\section{Cultura e identidade em São Paulo: A IMIGRAÇÃO SÍRIA E LIBANESA}

\author{
Marcia Maria Cabreira* \\ São Paulo não é uma cidade brasileira de 450000 habitantes, mas uma cidade \\ italiana de aproximadamente 100 000, uma portuguesa de talvez \\ 40 000, uma espanhola de igual tamanho e uma cidade pequena (kleinstadt) ale- \\ mã de mais ou menos 10000 habitantes, com pouca de suas vantagens e muitas \\ de suas desvantagens. Há ainda uns 5000 sírios, que sozinhos possuem três jornais \\ em caracteres arábicos. \\ (ERNST VON HesSE-WARTEG, viajante alemão da \\ primeira década do século XX)
}

REsumo: A finalidade deste artigo é refletir sobre a imigração síria e libanesa em São Paulo, entre 1870 e 1940, buscando entender quais os símbolos culturais que esse grupo étnico trouxe e que ainda estão presentes na sociedade paulistana e brasileira. Como base teórica dessa reflexão utilizamos o conceito de paisagem atrelado ao de memória e lugar, a partir da contribuição de intelectuais como Sauer, Berque, Sénecal e Bailly.

\section{Introdução}

O interesse pela imigração síria e libanesa para o Brasil surgiu há mais ou menos cinco anos quando, ao tentarmos levantar os documentos necessários para obter a cidadania italiana, encontramos, por acaso, a documentação de nossos avós e bisavós, imigrantes árabes. Esse interesse resultou em um estudo sobre a formação da comunidade síria e libanesa na cidade de São Paulo, entre 1870 e 1940. Recorremos a este recorte temporal por essas datas se referirem a dois momentos importantes na história da imigração para o Brasil: o ano de 1870 marca o incremento do número de imigrantes; o de 1940, o seu declínio.

A partir daí, uma questão nos intrigava: o porquê de a imigração árabe, apesar
PALAVRAS-CHAVE: imigração árabe; Rua 25 de Março; sírios e libaneses em São Paulo; mascates; imaginário.

\begin{abstract}
${ }^{*}$ Mestre e doutoranda em Geografia Humana (USP). Pesquisadora do Núcleo Interdisciplinar do Imaginário e Memória - NIME (Instituto de Psicologia-USP) e do Laboratório de Estudos do Imaginário (LABI-USP). Professora da Uninove, do Centro de Ensino Superior de São Caetano do Sul e do Colégio Brasília.
\end{abstract}

n. 1 
${ }^{1}$ A idéia de squemata, desenvolvida por Gombrich (1986: 5579), vem no sentido de explicar que, quando se procura retratar figuras/formas sobre as quais não há uma categoria prévia de interpretação ou conhecimento, o produto desse trabalho trará distorções. Reproduzem-se imagens e formas com base em um esquema com o qual se está familiarizado.

${ }^{2} \mathrm{O}$ termo é utilizado, neste texto, no sentido dado por Lévy-Strauss em Opensamento selvagem (Papirus, 1997). O que o caracteriza é o fato de operar com materiais fragmentários já elaborados, ou seja, utilizam-se idéias e imagens formuladas por um dado grupo étnico que, fora de seu local de origem, tem que ressemantizar sua cultura.

\footnotetext{
${ }^{3}$ Imaginário é entendido aqui como as representaçôes que a sociedade faz do que a cerca: como o mundo é percebido, concebido e, a partir disso, como as representaçôes são construídas. Isso significa que elas estão referidas, em primeiro lugar, à cultura da qual faz parte o grupo estudado.
}

de não ser tão marcante como a italiana ou a portuguesa, manter determinados aspectos de sua cultura presentes no cotidiano da cidade de São Paulo.

Para responder a essa questão, passamos a colher depoimentos dos descendentes mais antigos desses imigrantes e a fazer um estudo sobre uma parte da cidade que foi e ainda é fortemente marcada por sua presença: a Rua 25 de Março e adjacências, eleitas pelos sírios e libaneses e pelo resto da população paulista, como sendo a 'marca' dessa imigração. Interessava-nos entender como esses imigrantes construíram e reconstruíram sua identidade árabe na cidade de São Paulo, em outras palavras, como o Oriente se fez presente no Ocidente.

O lugar foi aqui analisado como espaço identitário, preenchido de símbolos que reportam a uma certa manifestação cultural. Como acontece a 'migração simbólica' para essa população? Pode-se dizer que a memória é um belo instrumento na moldagem do squemata ${ }^{1}$ para poderem 'domesticar' essa nova terra! Quando falamos em domesticar, estamos nos remetendo novamente à questão da identidade, ou seja, as pessoas precisam criar marcas, sinais para manter e dar continuidade a suas tradições e, com isso, fazer com que a cultura se torne dinâmica. É diante dessa dinâmica cultural que o imigrante atuará como um bricoleur ${ }^{2}$ para construir e reconstruir sua identidade. Assim, a paisagem passará a ser construída com o imaginário social dessa população, utilizando os símbolos da 'nova terra' com o sentido de suas tradições.

A memória aparece como um conceito central nessa análise. Ela é um dos recursos metodológicos para construir o imaginário do imigrante, e que nos permitiu traçar o imaginário da imigração síria e libanesa no Brasil. (HALBWACHS, 1990; NORA, 1997) $)^{3}$

\section{A imigração síria e libanesa em São Paulo}

Os primeiros imigrantes sírios e libaneses começaram a chegar ao Brasil por volta de 1870, embora existam alguns relatos registrando essa presença desde os séculos XVI-XVII que, no entanto, não nos permitem nomear como imigração. Os motivos que os fizeram imigrar são predominantemente dois: a ocupação pelo Império TurcoOtomano da Síria e do Líbano e a desagregação financeira que ocorreu com a entrada 
de França e Inglaterra naqueles países após a Primeira Guerra Mundial.

Ao chegarem ao Brasil, distribuíram-se praticamente por todo o território nacional, dedicando-se ao comércio. Apesar dessa dispersão pelo país, o estabelecimento na Amazônia e na cidade de São Paulo foi o que alcançou maior destaque.

Em São Paulo, fixaram-se inicialmente na área da Várzea do Carmo, ocupando principalmente a Rua 25 de Março e suas adjacências, como já dito. Até os anos 80, a rua ainda era vista como a 'rua dos turcos', imagem que começou a modificar-se com a chegada dos chineses e coreanos. Os terrenos mais baratos foram atraindo, pouco a pouco, uma camada menos favorecida em busca de trabalho e moradia. Desse modo, tanto as áreas de várzea quanto as áreas próximas das linhas férreas foram sendo ocupadas por um grande número de imigrantes que vinham para a cidade de São Paulo e não seguiam para as fazendas de café.

A origem da Rua 25 de Março está ligada à retificação do rio Tamanduateí, ainda em 1849. Porém, ela não tinha esse nome, tampouco o traçado que hoje conhecemos. De início, foi chamada de Caminho das Sete Voltas; depois, quando foi transformada em rua, denominou-se Rua de Baixo ou Rua Baixa de São Bento. Somente em 1865, é que foi oficialmente denominada Rua 25 de Março, nome dado em homenagem à primeira Carta Constitucional Brasileira. (MARQues, 1966: 84)

Um dos mais famosos memorialistas da cidade de São Paulo, Gabriel Marques, nos dá pitoresca descrição da Rua 25 de Março, no tempo em que o idioma predominante naquela área era o árabe e vários restaurantes de comida típica espalhavam-se pelas Ruas Abdo Schaim (antiga Rua Santo André), Cavaleiro Basílio Jafet e pela própria Rua 25, a fim de atenuar a saudade da terra de origem.

Repare! Veja como é cheia de vida e possui os raros encantos da nossa raça! É bem a nossa Bagdá Paulistana, sem califa, é claro, e sem as águas rumorejantes do 'Tigre’! Aqui se concretiza a divina recompensa do trabalho honesto e sem tréguas, da força de vontade sem desânimo, da persistência sem temores, e sempre da segurança dos que caminham em linha reta - convictos do triunfo final: a riqueza ganha com o suor do rosto! Sim, o dinheiro! O Luxo! (...) É rua colorida, alegre, gesticulante, com um cheiro gostoso de fazendas novas, tecidos gomados, de bons ou falsos perfumes e de sabonetes caros ou baratos. Ali há de tudo. Tudo que possa arregalar os olhos bisbilhoteiros se acha ali exposto em local bem visível. As vitrinas são, por 
isso mesmo, arlequinescas. Nelas nem faltam os tais velhos 'pentes-finos para caçar piolhos', nem mesmo o talco mal cheiroso para as senhoras suarentas. (...) Mil e um artigos dos mais atraentes são ali exibidos sem a menor parcimônia. Quinquilharias, sedas de boa e má qualidade, lenços, vestidos, meias - tudo! Tudo caro? Talvez sim! Talvez não! Depende da... da cara do freguês... (MARQues, 1966: 82)

Por esse trecho podemos ter uma idéia de como era o imaginário popular no que se refere aos imigrantes árabes e sua inserção no mundo comercial.

Quando iniciamos a pesquisa esperávamos encontrar, nas fotos antigas, um cenário que lembrasse a clássica imagem do Oriente. No entanto, quando olhamos uma foto de um trecho da Rua 25 de Março, datada de 1910, experimentamos um misto de surpresa e decepção por não termos visto os tecidos enfeitando a entrada das lojas, nem as portas e janelas construídas à maneira dos bazares árabes a que nos acostumáramos nas imagens dos cinemas e na literatura.

Foi por Bourdieu que entendemos o que estava 'atrás' desse aparente silêncio. Segundo ele:

Quando os dominados nas relações de forças simbólicas entram na luta em estado isolado, como é o caso nas interacções da vida cotidiana, não têm outra escolha a não ser a da aceitação (resignada ou provocante, submissa ou revoltada) da definição dominante da sua identidade ou da busca da 'assimilação' a qual supõe um trabalho que faça desaparecer todos os sinais destinados a lembrar o estigma (no estilo de vida, no vestuário, na pronúncia, etc.) e que tenha em vista propor, por meio de estratégias de dissimulação ou de embuste, a imagem de si menos afastada possível da identidade legítima. Diferente destas estratégias que encerram o reconhecimento da identidade dominante e portanto dos critérios de apreciação apropriados a construí-la como legítima, a luta colectiva pela subversão das relações de forças simbólicas - que tem em vista não a supressão das características estigmatizadas mas a destruição da tábua dos valores que as constitui como estigmas -, que procura impor senão novos princípios de divisão, pelo menos uma inversão dos sinais atribuídos às classes produzidas segundo os antigos princípios, é um esforço pela autonomia, entendida como poder de definir os princípios de definição do mundo social em conformidade com os seus próprios interesses (...). (1989: 124-125)

$\mathrm{O}$ primeiro passo para que um grupo seja aceito e inserido em um outro maior é parecer-se ao máximo com ele. Desse modo, ele poderá mostrar, aos 
poucos, suas diferenças. Pelo material analisado até o momento, esses imigrantes (como os de outros grupos) optaram por essa forma de 'aceitação' - suas lojas não se diferenciavam das demais lojas paulistanas; eram, sim, muito comuns.

A vontade de ser aceito e, portanto, reconhecido era muito grande. No depoimento do Sr. Samoel Atlas, pudemos ter um bom exemplo de como esse imigrante procurava, no seu cotidiano, construir essa aceitação.

Quando precisava de ajuda mandava buscar o irmão, o primo ou o filho em sua terra. Fazia com que o parente soubesse o nome da freguesia sem escrever. Para que ninguém interferisse no seu grande capital: a freguesia. E o imigrante não fazia só fregueses, fazia freguesas principalmente, mas ele fazia amigas. Ele se tornava amigo. [grifos nossos] (apud Greiber, Maluf \& MatTar, 1998: 206)

Esse desejo de aceitação nos faz refletir também sobre as questôes discriminatórias com relação a esse grupo, que não eram poucas. A fala gutural e o fato de comerem carne crua muitas vezes se traduziram em formas de não aceitação fora do grupo a que pertenciam. A pronúncia de algumas palavras (as letras $p$ e $v$ não existem no alfabeto árabe e o $g$ é pronunciado como $c$ : brimo por primo, fale por vale) e a dificuldade em distinguir o feminino do masculino tornaram-se, muitas vezes, motivo de chacota e piadas. Diegues Jr., em uma peça de teatro encenada em São Paulo entre os anos 20 e 30, cujo tema central partira da palavra arbatache (catorze em árabe), expõe de forma debochada a pronúncia desses imigrantes.

Outra forma comum de caçoada, de menosprezo era chamá-los de 'turcos'. Isso acontecia porque, com a invasão do Império Turco-Otamano, sírios e libaneses deixavam seus países utilizando passaporte turco. Ao chegarem aqui eram aleatoriamente chamados de turcos, o que lhes causava grande descontentamento e irritação. Nesse sentido, vale destacar que até hoje esse tipo de denominação causa aos descendentes um certo desconforto. Quando a criança começava a ir para a escola, era chamada pelas outras de 'turquinha'.

Apesar disso tudo, a maioria dos entrevistados negava ter havido algum tipo de conflito entre brasileiros, sírios e libaneses. Porém, pode-se perceber que as coisas não foram bem assim. Os conflitos aconteceram dentro da própria colônia ${ }^{4}$ e externamente a ela. Em seu depoimento, a Sra. Alice Maluf explica como foi seu contato com as demais mulheres que não eram árabes:
${ }^{4} \mathrm{~A}$ palavra colônia é normalmente utilizada pelos imigrantes como uma referência aos membros de mesma origem. 
Com esse depoimento podemos perceber que as coisas nem sempre foram fáceis e, para alguns, nem o tempo no Brasil foi capaz de tornar as diferenças menos duras.

Mas no campo do comércio essas diferenças se tornam mais diluídas. Como todos os outros imigrantes, sírios e libaneses vieram ao Brasil com o intuito de superar suas dificuldades econômicas e voltar para o seu país de origem.

Apesar desse forte apelo econômico, o trabalho era visto não só como uma fonte de acumulação e enriquecimento, mas também como uma forma de dignidade e (re)construção da identidade na nova terra. A idéia de vencer vem articulada com o trabalho. Essa postura é comum entre os entrevistados . O Sr. Jorge Germanos diz o seguinte: "Eu tratava de subjugar as dificuldades com a vontade de vencer e eu consegui”. (apud Greiber, Maluf \& MatTar, 1998: 683)

A idéia de vencer pelo trabalho vem preenchida por um conteúdo moral, muito importante para a construção da dignidade. Existe uma ética do imigrante a ser seguida, isto é, ele vem para vencer por seu trabalho. A idéia de que nem todos, apesar do trabalho, conseguiram chegar aonde queriam e de que entre eles existiam patrícios pobres foi encontrada entre poucos entrevistados. Prevalece a imagem do homem sofrido, do trabalhador que deu o sangue, mas que acabou ficando bem de vida.

É muito difícil encontrar relatos pessoais que falem dos imigrantes que não conseguiram 'se fazer'. As razões do insucesso são atribuídas a uma culpa individual: "Fulano não deu certo porque alguma coisa errada ele tinha: era vagabundo, bebia, jogava, divertia-se com mulheres".

O fato é que o enriquecimento se deu em uma determinada camada. E sem 
dúvida nenhuma a atividade de 'mascateação' foi um dos passos para o enriquecimento de boa parte dos que 'se deram bem'.

Não é possível falarmos da Rua 25 de Março sem nos referirmos à atividade de mascateação e à figura do mascate. Esta atividade é muito antiga: antes dos sírios e libaneses a praticarem no Brasil, portugueses, italianos e judeus já a exerciam.

No Brasil, costuma-se confundir mascate com caixeiro-viajante. Antes de entrar no estudo da mascateação no Brasil e no envolvimento dos sírios e libaneses com essa atividade, vale apontar as diferenças entre essas duas categorias ligadas ao comércio. Segundo a Confederação Nacional do Comércio, trata-se de atividades distintas. O mascate é um comerciante autônomo que vai se desfazendo do seu estoque à medida que seus artigos vão sendo vendidos. Já o caixeiro-viajante é um empregado que normalmente recebe comissōes sobre as vendas, é um 'tirador de pedidos', ou seja, vende aquilo que será entregue depois.

A figura do mascate é comparada pelos sírios e libaneses à do bandeirante paulista, que aparece na história como o herói desbravador dos sertôes. Essa imagem foi criada por causa de seu constante deslocamento.

O Sr. Samoel Atlas tem uma frase muito interessante para definir o mascate: "Quer dizer a estrada seguia o mascate, não o mascate seguia a estrada." Muitas vezes o mascate tomava o trem, descia na última estação e seguia ainda com baú lotado de mercadorias às costas ou no lombo de animal. Além da venda de mercadorias, freqüentemente era ele quem levava notícias de uma pessoa que estava em determinada cidade para sua família em outra. Portanto, era responsável pela chegada das novidades do comércio e das notícias.

Em São Paulo, a história desses homens está intimamente ligada à Rua 25 de Março. Este foi o lugar em que os primeiros imigrantes se fixaram e de onde os primeiros mascates partiam para vender em São Paulo ou no interior do estado. Nesse período, fim do século XIX e início do XX, a 25 de Março era conhecida como 'rua dormitório', uma vez que esses trabalhadores saíam com a luz acesa do quarto e retornavam na hora de acendê-la novamente.

\section{Últimas palavras...}

Como geógrafa, interessa-nos estudar as marcas que ainda permanecem no 
${ }^{5} \mathrm{O}$ termo é utilizado por Darnton (1988) para expressar o que é aparentemente opaco, sem importância.

KEY wORDS: Arabian immigration; 25 de Março Street; Syrian and Lebanese in São Paulo; peddler; imaginary. de nossa sociedade. Essas marcas e sinais estão naquilo que não se vê, o que Darnton denominou opacidade 5 . A opacidade e o silêncio são elucidados à medida que se opta pela interpretação do cotidiano, observando como se interpreta o mundo e quais significados lhe são atribuídos. A idéia de opacidade nos leva a entender que algo existe, apesar de ser nítido num primeiro olhar, pois o silêncio está preenchido de conteúdo. $\mathrm{O}$ fato de não se mencionar determinado assunto não significa, necessariamente, sua inexistência. $\mathrm{O}$ universo simbólico é visto como uma chave para o entendimento de alguns fatos. A dimensão da cultura e o trabalho do historiador etnográfico (DARNTON, 1988: 103-104) ajudam a entender o imaginário dessas pessoas que aqui chegaram, as formas de representação da realidade que trouxeram para o Brasil, as rotinas mantidas no cotidiano, ou seja, quais símbolos permanecem.

A polissemia do imaginário dos imigrantes pode ser percebida quando observamos o que aconteceu com a cidade de São Paulo, a partir de meados do século XIX, momento em que vários grupos étnicos vindos da Ásia e Europa transformaram, construíram e reconstruíram a paisagem existente. Há uma construção identitária do espaço, que se faz na intersecção dos símbolos culturais, do squemata com o lugar. Os sírios e os libaneses refizeram seu espaço vivido no Brasil, quando trouxeram seus aromas, suas ervas, seus costumes, que, de uma maneira ou de outra, foram sendo captados e ressemantizados pelas geraçôes posteriores.

A tradição, portanto, está presente na construção dessas 'novas paisagens' na América. É importante considerá-la porque a percepção que o indivíduo tem de seu lugar de origem é que vai guiá-lo no momento em que constrói o seu novo espaço, o seu novo modo de vida.

ABSTRACT: The article focuses Syrian and Lebanese immigration in São Paulo, between 1870 and 1940, trying to elucidate which symbols of those ethnic group are still present in 'paulistana' (from São Paulo city) and Brazilian societies. As theoretical fundament for this study we use the definition of landscape, connect to memory and place, using contributions of scholars like Sauer, Berque, Sénecal and Bailly.

\section{BiBLIOGRAFIA}

Alcântara, Maria de Lourdes Beidi de \& Sader, Maria Regina Cunha de Toledo. Paisagem e cultura. Revista Imaginário, São Paulo, Núcleo Interdisciplinar do 
Imaginário e Memória - Nime/Laboratório de Estudos do Imaginário-Labi, 5: 83-90, 1999.

Araujo, Oscar Egídio de. Enquistamentos Étnicos. Revista do Arquivo Municipal de São Paulo, São Paulo, 6: 231, mar. 1940.

Augé, Marc. O sentido dos outros. Petrópolis: Vozes, 1999.

Bastani, Tanus Jorge. O líbano e os libaneses no Brasil. Rio de Janeiro: F. Briguet, 1949.

. Memórias de um mascate. Rio de Janeiro: F. Briguet, 1949.

Bonnemaison Joël \& Cambrézy, Luc. Le lien territorial. Entre frontières et identités. Géographie et Cultures, Paris: 20: 7-18, hiver 1996.

Bour dieu, Pierre. O poder simbólico. Lisboa: Difel/Bertrand, 1989.

Br uno, Ernani Silva Bruno. História e tradiçôes da cidade de São Paulo. 3. ed. São Paulo: Hucitec/Prefeitura do Município de São Paulo - SMC, 1984. v. I, II e III.

Campos, Mintaha Aleuri. Turco pobre, sírio remediado, libanês rico: a trajetória do imigrante libanês no Espírito Santo (1910-1940). Vitória: Instituto Jones Santos Neves, 1987.

Candau, Joël. Anthropologie de la mémoire. Paris: Presses Universitaires de France, 1996. (Col. Que Sais-Je?)

Cor rêa, Roberto Lobato \& Rosendahl, Zeny (orgs.). Paisagem, tempo e cultura. Rio de Janeiro: Ed. UERJ, 1998.

Darnton, Robert. O grande massacre de gatos. 2. ed. Rio de Janeiro: Graal, 1988.

De Vos, George A. Ethnic pluralism: Conflict and accommodation - The role ethnicity in social history. In: Romanucci-Ross, Lola \& De Vos, George (eds.). Ethnic identity-creation, conflict, and accommodation. London: Altamira Press, 1995.

Deffontaines, Pierre. Mascates ou pequenos negociantes ambulantes no Brasil. Geografia, 2 (1): 27, 1936.

Faust o, Boris, Truzzi, Oswaldo, Grün, Roberto \& Sakurai, Célia. Imigração e política em São Paulo. São Paulo: Fapesp/Idesp/Ed. UFSCar, 1995. (Série Imigração)

Faust o, Boris (org.). Fazer a América. São Paulo: Edusp/Fundação Joaquim Nabuco/Memorial, 1999. 
Ferreira, Marieta de Moraes \& Amado, Janaína. Usos \& abusos da história oral. Rio de Janeiro: Fundação Getúlio Vargas, 1996.

Geertz, Clifford. A interpretação das culturas. Rio de Janeiro: LTC, 1989.

Go mbrich, Ernst H. Arte e ilusão. São Paulo: Martins Fontes, 1995. 384 p.

Greiber, Betty Loeb, Maluf, Lina Saigh \& Mat tar, Vera Cattini. Mémorias da imigração: libaneses e sírios em São Paulo. São Paulo: Discurso Editorial, 1998. $766 \mathrm{p}$.

Hajjar, Claude Fahd. Imigração árabe -100 anos de reflexão. São Paulo: Ícone, 1985.

Hal bwachs, Maurice. A memória coletiva. São Paulo: EdiçõesVértice/Revista dos Tribunais, 1990.

Hobsbawm, Eric \& Ranger, Terence. A invenção das tradiçôes. Rio de Janeiro: Paz e Terra, 1987.

Hourant, Albert. Uma história dos povos árabes. 2. ed. São Paulo: Companhia das Letras, 1995.

Knowlton, Clark S. Libaneses no Brasil, mobilidade social e espacial. São Paulo: Anhembi, 1960.

Kuczynski, Leila Mohamed Youssef. Libano - Impressóes \& cultura - Por uma líbano-brasileira. São Paulo: Distribuidora Paulista de Livros, 1994.

Kurban, Taufik. Sírios e libaneses no Brasil. São Paulo: Sociedade Impressora Paulista, 1933.

Le Goff, Jacques. História e memória. 3. ed. São Paulo: Ed. da Unicamp, 1994.

Lesser, Jeffrey. "O judeu é o turco de prestação": etnicidade, assimilação e imagens das elites sobre árabes e judeus no Brasil. Revista de Estudos Afro-Asiáticos, 27: 65-85, abr. 1985.

Lo pes, Carlos de São Thiago. São Paulo de hontem. São Paulo: Secretaria de Estado da Cultura/Divisão de Arquivo do Estado, 1998.

Marques, Gabriel. Ruas e tradições de São Paulo. São Paulo: Conselho Estadual de Cultura, 1966.

Mor se, Richard. Formação histórica de São Paulo. São Paulo: Difusão Européia do Livro. (Col. Corpo e Alma do Brasil)

Mour a, Paulo Cursino de. São Paulo de outrora - Evocações da metrópole. São Paulo: Edusp/Itatiaia, 1980. v. 25. 
Müller, N. L. Asp ectos da m etróp ole pauista. In: Azevedo, Aroido (org.). $A$ cidade de São Paulo - Estudos de geografia urbana. São Paulo: Nacional, 1958.

Nor a, Pierre. Les lieux de mémoire. Paris: Gallimard, 1997.

Ol iveir a, Lucia Lippi. O Brasil dos imigrantes. Rio de Janeiro: Jorge Zahar Editor, 2001.

$\mathrm{X}^{\text {th }}$ Int er nat ional Oral Hist ory Conference. Oral History: Challenges for the $21^{\text {st }}$ Century. Proceedings, Rio de Janeiro, v. 1, 2, 3, 14-18 june, 1998.

Pint o, Alfredo Moreira. A cidade de São Paulo em 1900. São Paulo: Secretaria da Cultura Ciência e Tecnologia, 1979.

Porto, Antonio Rodrigues. História da cidade de São Paulo através de suas ruas. São Paulo: Carthago, 1996.

Pout ignat, P. \& St r eiff-Fenart, Jocelyne. Teorias da etnicidade. São Paulo: Ed. Unesp, 1998.

Said, Edward W. Orientalismo - O Oriente como invenção do Ocidente. São Paulo: Companhia das Letras, 1996. Cultura e imperialismo. São Paulo: Companhia das Letras, 1999.

Sant'Anna, Nuto. São Paulo no século XVIII. São Paulo: Secretaria de Cultura, Ciência e Tecnologia/Conselho Estadual de Cultura, 1977.

Scapp, Ron \& Seit z, Brian (eds.). Eating culture. New York: State University of New York Press, 1998.

Serviço Nacional de Divulgação Cult ural Brasil eira. A imigração árabe no Brasil. História da Imigração no Brasil - As famílias. São Paulo, p.69-85.

Todorov, Tzvetan. Nós e os outros. Rio de Janeiro: Jorge Zahar Editor, 1993. v. 1.

Truzzi, Oswaldo Mário Serra. Patrícios - Sírios e libaneses em São Paulo. São Paulo: Hucitec, 1997. 254 p. (Col. Estudos Brasileiros, 31)

Sírios e libaneses e seus descendentes na sociedade paulista. In: Fausto, Boris (org.). Fazer a América. São Paulo: Edusp/Fundação Joaquim Nabuco/ Memorial, 1999. 
$\mathrm{E}$
$\mathrm{C}$
$\mathrm{C}$
$\mathrm{O}$
$\mathrm{S}$
$\mathrm{R}$
$\mathrm{E}$
$\mathrm{V}$.
$\mathrm{C}$
$\mathrm{I}$
$\mathrm{E}$
$\mathrm{N}$
$\mathrm{T}$.

n. 1
$\mathrm{v} .3$

jun.
2001


104 